\title{
General principles of spinal motor circuit development: early contributions from research on avian embryos
}

\author{
LYNN T. LANDMESSER* \\ Department of Neurosciences, Case Western Reserve University, Cleveland OH, USA
}

\begin{abstract}
Birds and mammals, both being amniotes, share many common aspects of development. Thus our understanding of how limb-innervating mammalian spinal motor circuits develop was greatly influenced by the use of the avian embryo (chick/quail) to bring about experimental perturbations to identify basic underlying mechanisms. These included embryonic surgery, the application of drugs to influence activity or molecular interactions, and the ability to observe motor behavior and make physiological recordings in intact developing embryos. This article will review some of these contributions, highlighting several areas including the acquisition of motoneuron subtype identity and target selection, as well as the role of spontaneous rhythmic activity in circuit development.
\end{abstract}

KEY WORDS: motoneuron specification, axon pathfinding, spontaneous activity, spinal cord

\section{Introduction}

Although initially trained as a neurophysiologist, as I began my independent scientific career in 1972 after becoming interested in understanding long-term trophic interactions between neurons and how circuits developed, my work was greatly influenced by the ability to use avian embryos to study neural development. With the rich array of tools available today, it is difficult to appreciate that at that time genetic approaches were not sufficiently developed to apply to questions at hand, there were no molecular markers for different subsets of neurons, and there were no means to trace the pathways of individual axons, as tract tracing methods such as HRP had not yet been invented. However my lab and many others were able to build upon the observations of a number of experimental embryologists, especially Victor Hamburger, who had popularized the use of avian embryos to study the development of limb innervation (Hamburger, 1939). Additional advantages of using the lumbar spinal cord were that motoneurons innervating specific muscles were known to occupy highly stereotyped positions and exit specific spinal nerves (Romanes, 1964) and thus were able to be identified by their position. Furthermore, due to extensive studies on the physiology of the spinal cord of adult cats (Grillner 1975), we knew in some detail what the spinal motor circuit actually did (unlike many other brain regions) as well as many of the specific connections, defined physiologically, that were made during development. Thus this system was ripe for exploration.

As evident from the other contributors to this issue, the use of avian embryos, pioneered by experimental embryologists such as Victor Hamburger, Nicole LeDouarin, and their many colleagues and students, contributed to our understanding of a number of important biological problems. Without this approach, progress on many of these problems would have been delayed for many years, awaiting the development of appropriate techniques. Given the topics covered by others in this issue, I will confine my remarks on how the use of such embryos contributed to our initial understanding of 1) How motoneurons acquire their subtype identities and find their synaptic targets, and 2) what spontaneous rhythmic activity revealed about spinal motor circuits and its role in motor circuit development.

\section{How motoneurons acquire their identities and find their target muscles}

In the early 1970's there was little understanding of how motoneurons became specified or how they connected with appropriate muscle targets. Although Ramon y Cajal (1911) had much earlier proposed that the growth cones of neurons actively navigated to their targets by responding to environmental signals (guidance cues), the idea that motoneuron growth cones could actively navigate over relatively long distances to reach limb muscles was not favored. Paul Weiss (1937) had instead, based on the behavior

Abbreviations used in this paper: D-V, dorso-ventral; PSA, polysialic acid.

\footnotetext{
*Address correspondence to: LynnT Landmesser. Department of Neurosciences, Case Western Reserve University, 10900 Euclid Ave., Cleveland OH $44106-4975$ , USA.Tel: (216) 368-3996. Fax: (216) 368-4650. E-mail: lynn.landmesser@ case.edu
} 
of transplanted amphibian limbs, proposed that motor axons grew out non-selectively and then obtained their identity from whichever muscle they innervated (myotypic specification). Others proposed (Horder and Martin 1978) that motor axons simply maintained a rough topographic order and were passively guided by mechanical features of the environment. Any errors in connectivity were proposed to be subsequently corrected by a poorly-defined process called "functional validation."

Although experimental embryologists had carried out many surgical perturbations (limb rotations, supernumerary limbs etc) and subsequent behavioral observations to distinguish among these alternatives, the lack of appropriate techniques did not allow an unambiguous interpretation of their results. Because multiple spinal nerves converge in one or more plexuses (avian hind limbs have two, crural and sciatic at the base of the limb), prior to the emergence of individual muscle nerves (Fig. 1A left), without axon tract tracing it was impossible to determine to which muscles axons from a given spinal nerve had projected either during normal development or following experimental perturbations. Thus many otherwise well conceived experiments yielded ambiguous results. Compounding the confusion and seeming to contradict the idea of active axon pathfinding was the observation that when foreign nerve fibers entered a transplanted limb bud, they formed a largely normal gross anatomical nerve pattern. As noted by Hamburger (1939), this clearly showed that the anatomical pattern of nerves within the limb was determined by factors in the limb itself. But without some form of axon tract tracing one could not determine how axons from given cord segments projected within the anatomical nerve pattern we later referred to as "a highway system." Similarly, the fact that motor axons could innervate a foreign muscle following experimental perturbations said nothing about selectivity of axon outgrowth during normal development.

We were able to overcome the tract tracing problem by electrically stimulating individual spinal nerves and recording from different muscle nerves (electrophysiological tract tracing). To our surprise, given the strong bias against specific axonal pathfinding, we found that each muscle nerve received axons from 2-3 specific spinal cord segments (Fig. 1A right) from the time axons first projected to muscles (Landmesser and Morrris, 1975). Thus motoneurons possessed at least a segmental identity and projected selectively to the same muscles innervated by those segments in the adult. A brief time later, when it became possible to retrogradely label motoneuron somas from specific muscles with HRP, the specificity of axon outgrowth could be extended to individual motoneuron pools (Landmesser, 1978). Although this method does not label axons, injection of HRP directly into motor nerves labels, via diffusion within axons, both somas and axons revealing the complete trajectories of axons from specific motoneuron pools. This approach showed that although axons from different motoneuron pools were extensively intermingled within proximal spinal nerves, they underwent a major re-organization at the base of the limb (Fig. $1 \mathrm{~A}, \mathrm{~B})$, first segregating into dorsal and ventral nerve trunks and subsequently into pool specific fascicles within major nerve trunks (Lance-Jones \& Landmesser, 1981a). Taken together these studies suggested that at the time motor axons exited the spinal cord they had motoneuron pool specific identities, presumably in the form of cell surface molecular differences, that enabled them to selectively sort into pool-specific fascicles and selectively pathfind to their target

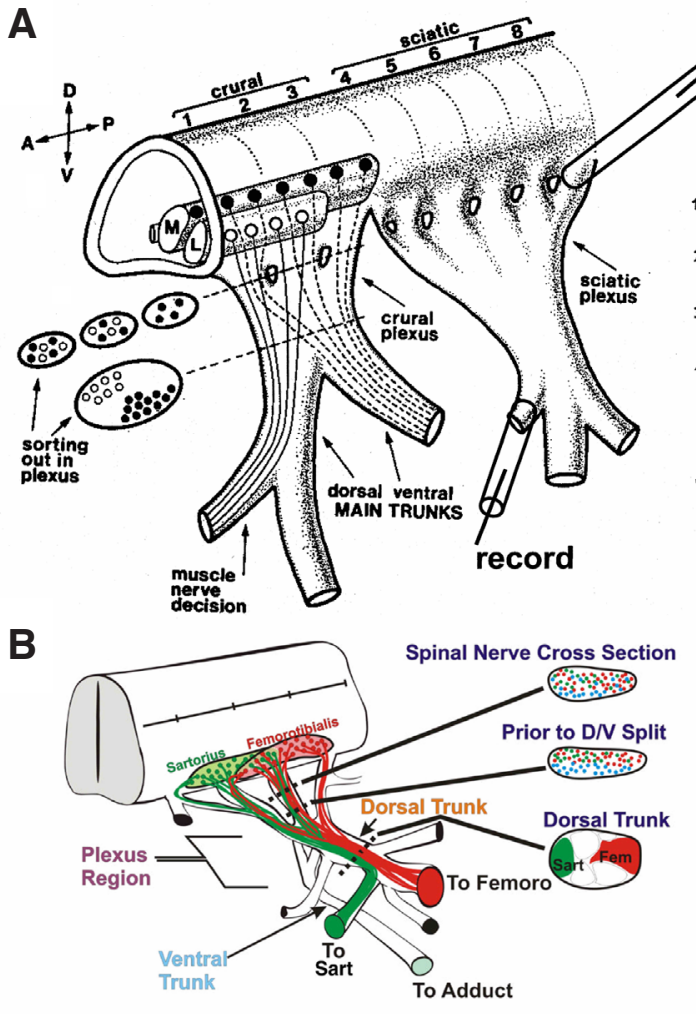

Fig. 1. Innervation pattern of the embryonic avian hindlimb based on electrophysiological and morphological axon tract tracing methods. (A, left) Anatomical nerve pattern showing eight spinal nerves converging into crural and sciatic plexuses prior to emergence of muscle nerves. The axons from one motoneuron pool in the lateral portion of Lateral Motor Column (open circles) and one from the medial portion (filled circles) are intermingled in proximal spinal nerves but then segregate into dorsal and ventral nerve trunks. (A, right) Prior to HRP tract tracing that let these trajectories be visualized, electrical stimulation of individual spinal nerves while recording compound action potentials from different muscle nerves (gastrocnemius versus peroneus) as muscles were first innervated (St28) showed that these each received axons from the same several segments as the adult innervation. (B) The axons from the sartorius (green) and femorotibialis (red) motoneurons pools (both $L M C l)$ are intermingled in the proximal spinal nerves but then segreate dorsally from ventrally projecting adductor axons (blue) at the D-V choice point. They subsequently segregate into muscle specific fascicles within the dorsal nerve trunk before projecting to their muscles. (C) More schematic view of $D$ - $V$ and pool-specific pathfinding choices. Medial islet-1 expressing

motoneurons (red) and lateral Lim-1 expressing ones (green) first make the D-V pathfinding choice. Then the axons of individual dorsally projecting pools (light green, femorotibialis; dark green, sartorius) segregate into pool-specific fascicles before projecting to individual muscles. 
A

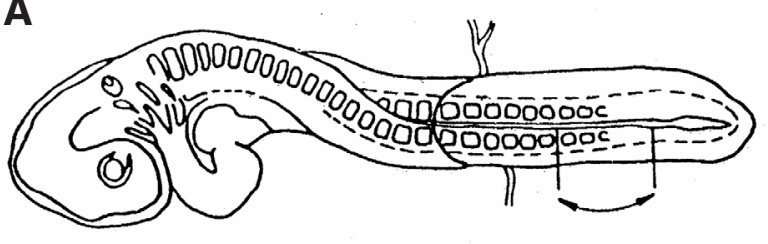

B

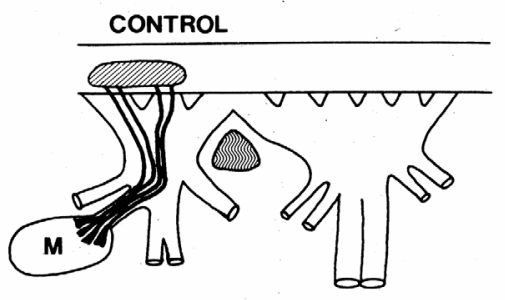

C

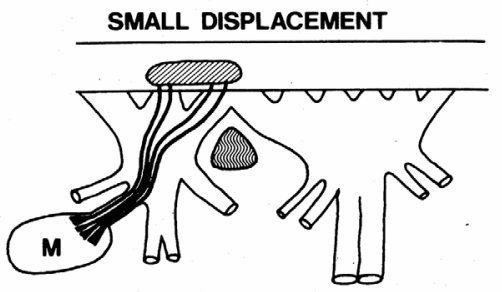

D

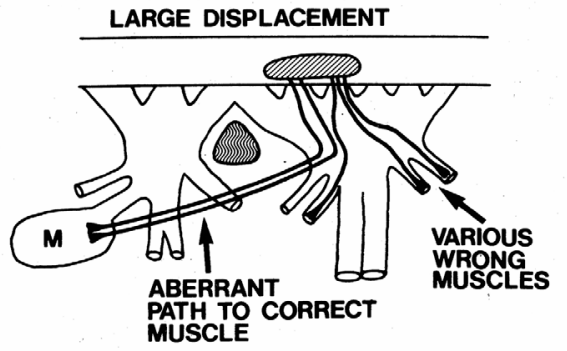

muscles. How then could these findings be reconciled with other reports of non-selective innervation (Stirling \& Summerbell 1981)?

This apparent conflict was resolved by displacing motoneurons varying distances from their normal targets by either surgically moving portions of the neural tube (Fig. 2) or by rotating limb buds in early (St-16-17) chick embryos (Lance-Jones and Landmesser, 1981b). When dispaced moderate distances so that the axons entered their original plexus, they altered their trajectories within the plexus to project to their original muscle. When displaced larger distances and entering the wrong plexus most projected to a variety of foreign muscles within the anatomical nerve pattern imposed by that part of the limb. However, some axons, ususally those closest to their original target, deviated from the normal anatomical nerve pattern and grew via completely novel pathways to reach their appropriate muscles.

Although no axonal guidance cues had been identified at that time, the simplest explanation to explain the experimental results would be that the limb imposed branching pattern was likely caused by the distribution of either repulsive and/or attractive guidance cues within the limb to which all motoneurons could respond, and was therefore permissive. In addition, more specific guidance cues to which only subsets of motor axons could respond were required to explain the choice of lateral and medial Lateral Motor
Fig. 2. Embryonic surgery to elucidate motor axon pathfinding and the cues which mediate it within the limb bud. (A) Portions of neural tube were displaced varying disatances along the A-P axis at St 16. (B) Control; axons from a single motoneuron pool enter the crural plexus via several spinal nerves and project to correct muscle. (C) When displaced a moderate distance, the axons enter via different spinal nerves but then alter their trajectory in the plexus to project to correct muscle. (D) Following large displacement and entering to wrong sciatic plexus, most axons project to a variety of foreign muscles. However some closer to the original target deviate from the control anatomical nerve pattern and reach the original muscle via novel or aberrant pathways that axons never follow in control embryos.

Column (LMC) axons to select the dorsal or ventral nerve trunk respectively (Fig. 1C), and for the grouping of motor axons into pool-specific fascicles at specific A-P and D-V locations within the plexus and major nerve trunks. Finally, muscle-specific cues would subsequently enable motor axons to leave main nerve trunks and project to target muscles via muscle nerves. The fact that following relatively large displacements some axons were still able to reach their muscle targets via a variety of novel pathways, indicated that the muscle-specific cues were not confined to the limb imposed anatomical nerve pattern, suggesting that axons may be responding via chemotaxis to a gradient of an attractive signal. This presumambly does not extend across the entire limb bud since with greater displacements axons from an individual motoneuron pool simply projected to a variety of foreign muscles.

What tissues were producing these cues? Although motoneurons from given cord segments normally innervate muscles whose myogenic cells migrate from somites at the same segmental level, somite transplantation experiments showed that motoneurons would innervate muscles derived from different somitic levels (Keynes et al., 1987; Lance-Jones, 1988). Furthermore, when limbs completely lacking muscle fibers were created by removing all somites, specific motoneuron pools still projected selectively to the location where their muscle would have been (Phelan and Hollyday, 1990). These observations, suggesting that muscle specific cues arose not from the myogenic cells in the limb but from presumptive connective tissue derived from the somatopleure, were supported by a subsequent study in which the somatopleure was shifted rostrally along the A-P axis (Lance-Jones \& Dias, 1991). Intriguingly in this study, axons from anterior lumbar segments that entered the sciatic plexus also took novel pathways through the limb to project to their original muscles, as observed in Lance-Jones \& Landmesser 1981b). Taken together, these observations suggest that non-specific limb imposed cues and motoneuron pool-specifc pathfinding cues are normally congruent, giving rise to the relatively fixed anatomical and pool-specific nerve pattern. However, when non-congruent following experimental perturbations, specific cues were to some extent able to override the limb imposed cues enabling some axons to project to their target muscles via novel pathways. In parallel with these studies on avian embryos, work in grasshopper embryos and subsequently Drosophila (Goodman et al., 1984; Bentley and Keshishian, 1983) provided convincing evidence for selective axon pathfinding, which is now universally accepted.

These early experiments on avian embryos provided a general understanding of the types of pathfinding cues used by spinal cord neurons to navigate the limb and the tissues from which they 
arose. They also provided evidence that motoneurons possessed pool-specific molecular identities from the time of axon outgrowth. However, a more detailed understanding awaited the molecular identification of such cues and the receptors which detected them, as well as the genes that conferred motoneuron identity. Over the next several decades many labs using a variety of approaches in vertebrates as well as invertebrates provided a deeper understanding of pathfinding by characterizing many attractive as well as repulsive guidance cues and their receptors, and showing they could act as long range gradients or be contact dependent as summarized in the Tessier-Lavigne and Goodman (1996) review. The identification of signals that pattern the spinal cord on the $\mathrm{D}-\mathrm{V}$ axis (defining motoneurons and subclasses of interneurons) and the A-P axis (defining motoneuron columnar and pool specific identity) are summarized in Catela et al., 2015).

A key observation in advancing our understanding of how different subclasses of motoneurons developed distinct columnar identities related to their target choice was made by Tsuchida et al.,1994). They discovered that in embryonic chick cord, the LIM homeodomain transcription factors Lim-1 and Islet- 1 were selectivly expressed in lateral and medial LMC motoneurons respectively and that this correlated with their dorsal or ventral pathfinding choice at the base of the limb (Fig. 1C). Susbsequent genetic deletion of Lim-1 in mice randomized the choice $\mathrm{LMCl}$ axons made in selecting the dorsal or ventral pathway whereas LMCm, Islet-1 expressing, motoneurons continued to make their approriate ventral choice (Kania et al., 2000). The selective restriction of the tyrosine kinasae receptor EphA4, known to cause growth cone collapse upon binding its ephrin ligand, to chick LMCI distal axons at the time of the D-V pathfinding choice, together with the expression pattern of its ephrin ligands in the limb suggested a major role in D-V pathfinding (Eberhart et al., 2000). This role was confirmed in subsequent studies (Eberhart et al., 2002; Kania and Jessel 2003) by using in-ovo electroporation of tagged plasmid contructs into chick neural tubes to cause ectopic expression of EphA4 in LMCm motoneurons and showing that it caused many to project dorsally. Subsequently EphB1, expressed on LMCm axons was shown to be important for appropriate ventral pathway selection (Luria et al., 2008). However, it is now widely appreciated (Kramer et al., 2006; Poliak et al., 2015) that even a simple binary pathfinding choice as in $\mathrm{D}-\mathrm{V}$ pathway selection involves the integration of multiple molecules and signaling pathways.

Although more recent studies have used genetic alterations in mice to alter the expression of a variety of molecules, at that time in-ovo electroporation provided a way to rapidly alter the expression of different genes/molecules and determine how this affected pathfinding, neuronal identity, or other apsects of spinal cord-limb development. Fortunately, due to the strong conservation in birds and mammals of both molecules and cellular mechanisms used during spinal cord development, results obtained with in-ovo electroporation were usually relevant to the mouse and provided insight into which mouse genetic alterations should be pursued.

While individual motoneuron pools clearly selectively targeted and synapsed with appropriate peripheral targets, it was not clear if they had also made selective connections with appropriate interneurons in the spinal cord required for normal locomotion. Avian embryos exhibit bouts of spontaneous limb motility from E7 (stage 30). when muscles are first innervated. Although such movements, viewed through a window in the egg, appeared jerky and uncoor- dinated, by making in-ovo EMG recordings Anne Bekoff found that even at this early stage the antagonistic flexor and extensor muscles in the shank were activated appropriately out of phase (Bekoff et al., 1975). These obervations indicated that early in development the spinal cord contains pre-motor circuits capable of activating antagonistic muscles appropriately, and that motoneuron pools had also made appropriate connections with these circuits. More recent studies, largely from the Arber lab, have defined both the molecular identity and the spatial position of flexor and extensor pre-motor interneurons (Tripodi et al., 2011). They and others have also shown that the spatial location within the cord may be important for facilitating specific connectivity between motoneurons and pre-motor interneurons (Tripodi and Arber 2012). It is interesting that early studies in embryonic chicks showed that even when motoneurons were caused to innervate foreign muscles following surgical perturbations, they maintianed their original pool-specific bursting patterns, including flexor vs flexor patterns (Landmesseer and O'Donovan 1981a,b), providing clear evidence against myotypic specification. However, while many early studies cited above showed that motoneurons possessed many pool-specific properties prior to their innervation of the limb, we now realize that signals dervied from the limb also contribute to the proper connectivity of some motoneuron pools and proprioceptive sensory neurons (Haase et al., 2002; Patel et al., 2003).

\section{Rhythmic spontaneous bursting activity and its role in spinal motor circuit development}

It is now appreciated that in both birds and mammals highly rhythmic, spontaneous episodes of bursting activity are widespread throughout the developing nervous system including the retina and spinal cord (Blankenship and Feller, 2010). This activity is in the form of network driven propagating waves and in amniotes its many conserved properties distinguish it from the embryonic activity observed in other vertebrate and invertebrate species. I will first review how the properties of this activity and the mechanismsms that generate it were discovered using avian embryos. I will then highlight several examples to show its critical role in several aspects of spinal cord and muscle development (for more complete review see Moody and Bosma 2004).

Pioneering behavioral studies by Hamburger and colleagues on chick embryos showed that such activity was highly rhythmic and that it began as S-shaped propagating waves of axial movement as early as E4 (St 23) prior to motoneuron outgrowth into the limb, but by $\mathrm{E} 7$ (St30) the limbs were also activated during these waves (Hamburger and Balaban, 1963). Importantly these studies provided evidence that this early activity was centrally generated since relexes could not be elicited until E 7.5 (St 31) when sensory afferents are known to begin to project into the spinal cord and form synapses. The central generation of this activity was further confimed by showing that it was still generated following embryonic surgery that removed descending input from the brain as well as sensory input (Hamburger et al., 1966). While Hamburger and colleagues also showed that these bouts of motility were associated with electrical bursting activity in the cord (Provine et al., 1970), subequent characterization of the circuits generating such activity was greatly facilitated when it was found to also occur in isolated chick spinal cords where pharmacological perturbations and more extensive electrical recordings were possible (O'Donovan and 
Landmesser 1981a).

O'Donovan and colleagues subsequently characterized in some detail the circuits driving rhythmic activity using both electrophysiology and $\mathrm{Ca}^{2+}$ imaging (O'Donovan et al., 1998). Thus, although specific pre-motor lumbar circuits activated muscles with locomotor-like patterns during bursting episodes both in-ovo and in isolated spinal cord preparations (Bekoff et al., 1975; Landmesser and O'Donovan, 1981a), the circuit responsible for generating repeated episodes of rhythmic activity was a much more diffuse network of motoneurons and interneurons with extensive reccurent excitatory connections. Waves, which propagated in both directions, were initiated when sufficient excitation built up, and although all cord segments were capable of generating them, at any point in time they were generated by the most excitable part of the circuit. Following an episode, a period of network depression prevented the premature initation of another wave, thus providing the highly rhythmic nature of spontaneous activity (Tabak et al., 2001). More recent studies using imaging of voltage sensitive dyes in both isolated chick and mouse brain-spinal cord preparations have confirmed and extended these studies, showing that at early stages waves originate in the cervical or lumbar cord and propagate both caudally as well as anteriorly into brain structures (Momose-Sato et al., 2012a). It is amazing that so many of the general properties of these early waves were actually deduced by the careful behavioral studies of Hamburger and colleagues many years before (Hamburger and Balaban, 1963; see also Bekoff 2001).

To determine what role, if any, such activity plays during development requires that it be blocked in-vivo during defined periods. The following features of this circuit, elucidated in both chick and mouse, are most relevant for achieving this goal. First, at early stages as motor axons are growing into the limb, ACh released by motoneurons provides an essential excitatory drive with GABA and glycine also contributing as they are excitatory at this developmental stage (Nishimaru et al., 1996; Milner and Landmesser, 1999; Hanson and Landmeser 2003; Momose-Sato et al., 2010b). As muscles become innervated, the excitatory drive switches to glutamate while GABA and glycine become inhibitory as in the adult. A second important feature is that strong homeostatic mechanisms resist attempts to perturb activity. Thus while both early and late activity can be blocked by nicotinic or glutamatergic antagonists respectively, this is only transient, with activity returning within hours and now being driven by GABA (Chub and O'Donovan, 1988; Milner and Landmesser, 1999). Thus while developing rodent and chick spinal circuits have similar properties, a great advantage of the chick is that the effect of any perturbation on activity (pharmacologic or optogenetic) can be precisely determined over long time periods since every wave elicits a clearly detectable movement that can be monitored via a window in the egg. This is not possible in the in-vivo mouse embryo.

\section{Effects of altering activity after muscles have been innervated}

Another advantage of avian embryos is the possibility to apply drugs to activate or block specific transmitter receptors over defined time periods. Pittman and Oppenheim (1978) found that the nicotininc antagonist dTC applied from the time of muscle innervation (E7, St 30) blocked spontaneous motility and rescued lumbar motoneurons from programmed cell death, a period from
E7-E10 (St30-36) when half the motoneurons normally die (Hamburger,1975). It was appreciated at that time that motor neurons depended for survival on target derived trophic factors, since studies in chick embryos had shown that most motoneurons died following limb bud removal (Hamburger, 1934) and that survival was increased by peripheral target enlargement following supernumerary limb bud transplantation (Hollyday and Hamburger, 1976). Muscles apparently were the source of the survival factor(s) since most motoneurons died during this same period when innervating A
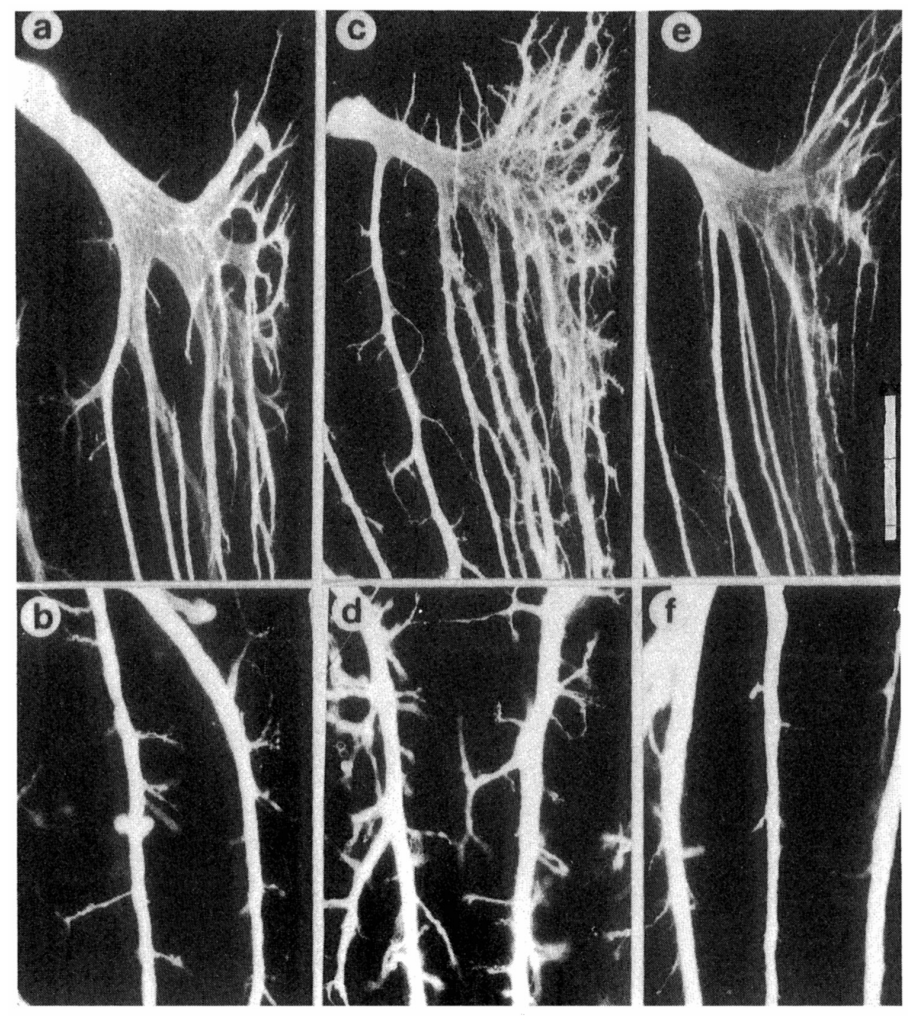

B
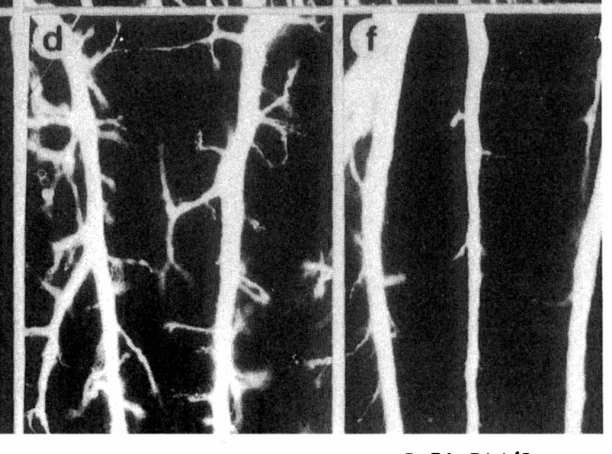

$5+32-33$

$5+34-341 / 2$

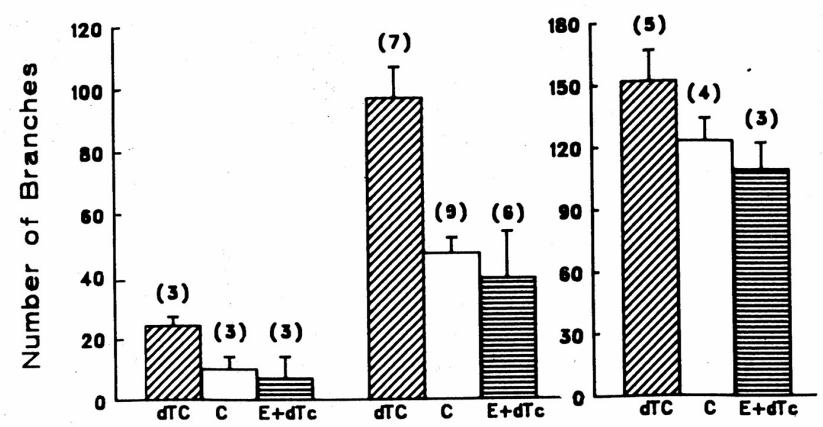

Fig. 3.The effect of blocking spontaneous activity on the intramuscular nerve branching pattern and how this is altered by removal of polysialic acid (PSA) on axons. (A) Muscle whole mounts of the iliofibularis muscle show the axon branching pattern in the fast region (top) and slow region (bottom). (a,b) Control; (c, d) the large increase in branching following activity blockade with the nicotinic antagonist dTC. (e,f) Prevention of this increase by removing PSA from NCAM via local in-ovo injection of a PSA-specific endosialidase, endo-N. (B) Quantification of the number of branches in the slow region in the control (C), actvity blockade (dTC) and activity blockade + PSA removal $(E+d T C)$. 
muscleless limbs (Phelan and Hollyday, 1991).

One possibility was that blockade of activity resulted in an increase in the production or release of trophic factors from muscles and some evidence supports this (Oppenheim, 1991). However blockade of muscle activity also resulted in a large increase in intramuscular nerve branching (Fig. 3 A,B) of motor axons in chick thigh muscles (Dahm and Landmesser, 1989). This subsequently resulted in a doubling in neuromuscular synapses early in the cell death period when synapses first formed (Dahm and Landmesser, 1991; see also Ding et al., 1983 who found an increase in synapses but at a later time point). These observations gave rise to the idea that the increased number of synapses as a result of excessive nerve branching might enhance survial by enabling more efficient uptake of trophic factors.

One caveat of in-ovo drug injections is that antagonists/agonists will bind to all of the targeted receptors; thus dTC would bind to nicotinic receptors in muscle, spinal cord or elsewhere, possibly causing non-specific effects. It was reasurring, therefore, that many of the effects on muscle development that were observed when blocking nicotinic receptors in the chick, including increased intramuscular nerve branching, increased number of synapses, and the prevention of programmed motoneuron cell death, were observed when choline acetyltransferase, the enzyme that synthesizes ACh, was genetically deleted in the mouse (Brandon et al., 2003). In this mouse release of ACh from motoneurons would not occur, thus preventing muscle fiber activation as well as blocking spontaneous, cholinergic driven, activity at early stages. However, a more specific alteration, the genetic deletion of the muscle-specifc ACh receptor, $A C h R \alpha 1$, was later shown to result in increased intramuscular nerve branching and motoneuron survival (An et al., 2010). These results show the importance of activating muscle AChRs in regulating the extent of intramuscular nerve branching and synapse formation, but it is important to note that such activation would also be reduced if early cholinergic-mediated activity was blocked, even withoutblocking muscle-specific $A C h$ receptors.

The example cited above will now be used to illustrate an additional benefit of using avian embryos, even in what has become the era of genetic approaches. The studies described above estabished a correleation between the extent of intramuscular nerve branching and motoneuron survival following activity blockade. A futher test of this idea would be to alter intramuscular nerve branching without altering activity and determine its effect on motoneuron survival. Although virtually nothing was known about the molecular basis of such branching at that time, we were lucky to observe (Landmesser et al.,1990) that activity blockade caused a large increase on intramuscular motor axons of polysialic acid (PSA), a carbohydrate added to NCAM that decreases axon-axon fasciculation (Rutishauser and Landmesser, 1996). We therefore reduced $P S A$ locally by injecting in-ovo into one thigh a PSAspecific endosialidase, endo- $\mathrm{N}$, and confirmed the spatial and temporal extent of PSA removal via immunostaining. Endo $\mathrm{N}$ reduced the extent of branching in control animals and completely prevented (Fig. 3 A,B) the increased branching caused by activity blockade (Landmesser et al., 1990). We also found that injection of a highly purified antibody Fab fragment against L1, an adhesion molecule increasing axon-axon fasciculation, could reverse the effects of endo- $\mathrm{N}$ on branching. While synapse formation and motoneuron survival were not quantified at that time, it was subsequently shown that endo-N injection in control embryos reduced both the number of intramuscular nerve branches and motoneuron survival without affecting activity (Tang and Landmesser, 1993).

These observations illustrate that the ability to alter quite locally and for defined time periods, the expression or function of molecules, and even their postranslational modifications is a great advantage not easily achieved by even modern day genetic techniques. Especially for neurons that extend axons long distances, in some cases to different targets via axon collaterals, local regulation of cell surface adhesion and guidance molecules is essential. Thus the amount of a given molecule in the surface of an axonal growth cone at a given time or place, may not reflect its message level in the cell body but be regulated by local translation, stabilization on the cell surface, or enzymatic cleavage (O'Donnell et al., 2009; Holt and Schuman, 2013).

\section{Effects of altering spontaneous activity early in development and prior to muscle innervation}

In birds and mammals many aspects of spinal cord development, including the differentiation of subtypes of interneurons and motoneurons, is activity independent. Although activity was shown to refine axonal projections later in development, initial axon pathfinding was thought to be activity independent (Katz and Shatz, 1996). Nevertheless, the $\mathrm{Ca}^{2+}$ transients associated with bursts of activity had been shown to regulate the rate of axonal extension in different species, and electrically stimulating cultured Xenopus spinal neurons altered their interpretion of a gradient of myelin associated glycoprotein from inhibitory to attractive (Ming et al., 2001). However given the complexity of individual pathfinding choices in-vivo, it was essential to alter activity in the intact developing embryo and determine its effect on pathfinding.

Given that complete blockade of spontaneous activity is highly unphysiological and could induce complex homeostatic responses, we chose to block $\mathrm{GABA}_{\mathrm{A}}$ receptors in-ovo with picrotoxin as this resulted in only a modest $(2 X)$ reduction in the frequency of the spontaneous episodes of activity. Furthermore, this decrease was maintained during the entire period (St 23-28) of motor axon outgrowth (Hanson and Landmesser, 2004). We oberved that defasciculation of motor axons at the plexus was reduced and that approximately $20 \%$ of motoneurons made D-V pathfinding errors. These changes were associated with a reduction, assessed by immunostaining, of several guidance cues known to be important for this pathfinding choice: PSA on NCAM which enables axons to defasciculate and respond to other more specific guidance cues(Tang et al., 1992), EphA4 on dorsally projecting LMCl axons (Kania and Jessell, 2003), and EphB1 on ventrally projecting LMCm axons (Luria et al., 2008). These changes were limited to distal axons near the choice point and their expression in the spinal cord or on more proximal axons was not altered nor was EphA4 messsage in LMCI motoneurons (Hanson and Landmesser, 2004).

To determine if only some level of activity was needed to enable axons to respond to cues regulating this choice (i.e. acting in a permissive manner), or if motor axons were sensitive to the precise frequency of activity episodes, we next increased the frequency (2X) by application of the glycine uptake inhibitor sarcosine (Hanson and Landmesser, 2006). Surprisingly this increase in frequency did not cause D-V pathfinding errors or alter the expression of EphA4, EphB1, or PSA, but it profoundly disrupted pool-specific pathfinding. Thus deviations from the normal frequency of spontaneous activ- 
ity in either direction perturbed pathfinding but in different ways, indicating the importance of maintaining the normal frequency. One caveat to these approaches was, that in addition to altering the frequency of episodes, the applied drugs were also either blocking $\mathrm{GABA}_{\mathrm{A}}$ signaling or enhancing glycinergic signaling. We therefore decided to apply an optogenetic approach for which chick embryos were especially advantageous.

Fluorescenly tagged constructs of ChR2 were electroporated into the cervical cord of St 18 embryos causing ChR2 to be expressed in both motoneurons and interneurons (Fig 4 A,B). Brief flashes of light were used to drive spontaneous waves of activity that then propagated into the lumbar cord throughout the period of motor axon outgrowth. Two sets of experiments were carried out. In the first we applied picrotoxin to block GABA $_{A}$ signaling but then drove waves at the normal frequency with light from St 20 on (Fig. 4C). This rescued both the D-V pathfinding errors (Fig. 4D) and the expression of PSA, EphA4, and EphB1 in the plexus

A

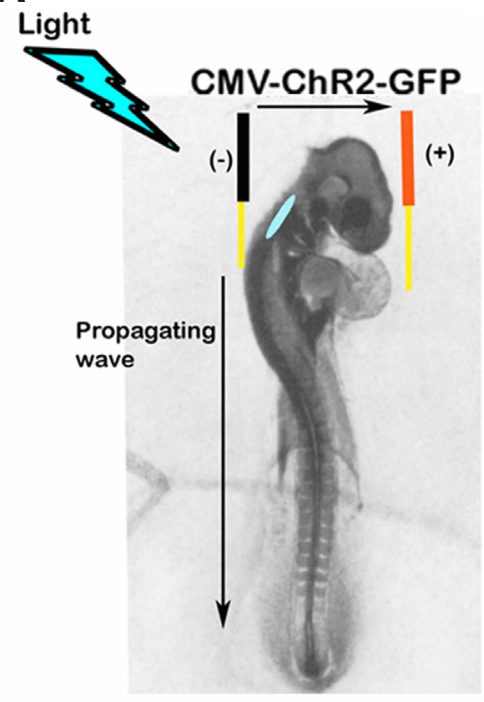

\section{C}

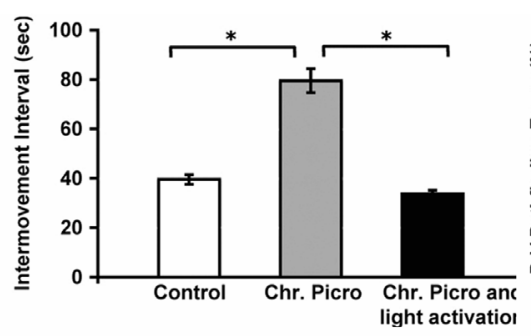

B

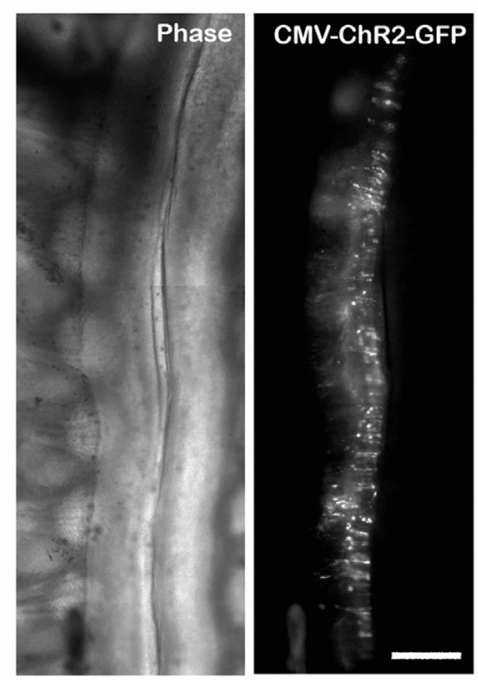

D

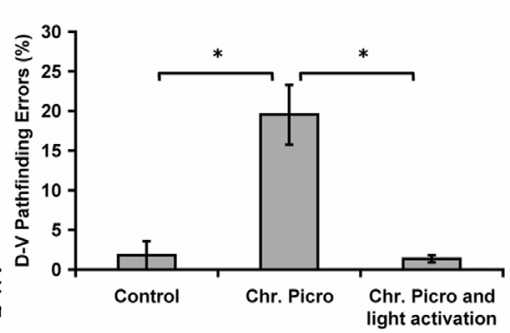

Fig. 4. An optogenetic approach to alter spontaneous activity in vivo and its effect on dorso-ventral (D-V) pathfinding. (A) At St18 GFP-tagged ChR2 was electroporated into the cervical neural tube of chick embryos. (B) Phase and fluoresecnt views of cervical cord at St 25 showing expression of ChR2 on the electroporated side. Activation of ChR2 by light flashes caused waves to propagate into the lumbar cord. (C) The intervals between spontaneous waves was increased from control values by slowing spontaneous activity with chronic in-ovo application of picrotoxin to block GABA transmission (Chr. Picro). This could be reversed by eliciting waves at the control frequenccy in picrotoxin treated embryos (Chr. Picro and light activation). (D) Slowing the frequency with picrotxin caused $20 \%$ of motor axons to make D-V pathfinding errors, and these were rescued by driving waves at control frequency.
(Katsanenka and Landmesser, 2010). In the second, we used flashes of light to double the frequency of waves and found that neither $\mathrm{D}-\mathrm{V}$ pathfinding nor the expression of the $\mathrm{D}-\mathrm{V}$ guidance cues were altered. However pool-specific pathfinding was severely compromised (Kastanenka and Landmesser, 2013), as found previouly by increasing the frequency of spontaneous activity with sarcosine (Hanson and Landmesser, 2006).

Taken together these findings indicate that this system is senstive to modest increases or decreases in spontaneous bursting episodes and their associated $\mathrm{Ca}^{2+}$ transients. This is not without precident as the expression of different adhesion molecules (Itoh et al., 1997) as well as transcription factors (Watt et al., 2000) has been shown to be sensitive to different stimulus frequencies. Furthermore, both the pattern and frequency of stimulation $/ \mathrm{Ca}^{2+}$ transients can differentially regulate gene expression (Dolmetch et al., 1997). Nevertheless, several recent studies have challenged our results by indicating that D-V pathfinding and EphA4 expression were not altered when activity was blocked by exogeneous expression of a $\mathrm{K}^{+}$channel (Benjumeda et al., 2013) or by the genetic deletion of a SNARE protein needed for exocytosis of synaptic vesicles (Law et al., 2016). It is important to point out that these were, in fact, very different experiments; in the latter cases activity was completely blocked, whereas we only modestly altered the frequency of spontaneous episodes. The expression of some molecules and the execution of some pathfinding decisions may occur in the complete absence of activity and a number of molecular events are clearly activity independent. However, the complete absence of electrical activity would almost never be experienced by a developing nervous system. Our results show instead, that when the pattern and/or frequency of spontaneous activity is altered, as would occur with a variety of mutations that affect different transmitter systems, or in the case of maternal drug use affecting such systems, early developmental events, such as pathfinding can, in fact, be affected.

Finally, it is interesting to recognize that all amniotes that have been studied have propagating waves of activity with many conserved properties, even when occuring in vastly different neuronal structures such as the spinal cord or retina: 1) they all have similar low frequencies with highly rhythmic episodes being separated by relatively long intervals $(30-100 \mathrm{sec}), 2)$ they propagate at similar relatively slow velocities $(10 \mathrm{~mm} / \mathrm{sec})$, and 3 ) many show a similar switch in excitatory drive from ACh or GABA to glutamate. Unlike other vertebrates such as zebrafish or Xenopus, or many invertebrates, where embryos or larvae actively move and receive sensory stimuli very soon after gastrulating, amniotes, contained within the uterus or rigid eggs, would experience long periods of time completely devoid of exogenous stimulation and thus activity. As has been noted (Ackman and Crair, 2014), amniotes may have evolved to have waves of propagating activity to activate the nervous system and muscles in a regular way prior to the development of sensory systems capable of detecting exogeneous stimuli. Downstream molecular mechanisms may have also evolved to have a preferred frequency of $\mathrm{Ca}^{2+}$ transients. While highly speculative this is an interesting possibiity to consider. 
Concluding, I hope that the individual examples I used to illustrate major points have been able to convey that early studies using avian embryos provided a good conceptual understanding of the major principles of how spinal motor circuits form. This work therefore provided a strong foundation for more recent work utilizing genetic and other more modern approaches to better dissect the underlying mechanisms at the cellular and molecular levels. I also apologize to the many scientists who also made important contributions to this area but whose work was not cited due to space constraints.

\section{References}

ACKMAN JB, CRAIR MC (2014). Role of emergent activity in visual map development. Curr Opin Neurobiol 24: 166-175.

AN MC, LIN W, YANG J, DOMINQUEZ B, PADGETT D, SUGIURU Y, ARYAL P, GOULD TW, OPPENHEIM RW, HESTER E, KASPAR BK, KO C-P, LEE K-F (2010). Acetylcholine negatively regulates development of the neuromuscular junction through distinct cellular mechanisms. Proc. Natl. Acad. Sci. USA 107: 10702-10707

BEKOFF A (2001). Spontaneous embryonic motility: an enduring legacy. Int J Devl Neurosci 19: 155-160.

BEKOFFA, STEIN P, HAMBURGER V (1975). Coordinate motor output in the hindlimb of the 7 day chick embryo. Proc Nat Acad Sci 72: 1245-1248.

BENJUMEDAI, ESCALANTEA, LAW C, MORALESD, CHAUVING, MUCAG, COCA Y, MARQUEZ J, LOPEZ-BENITO G, KANIAA, MARTINEZ L, HERERRAE (2013). Uncoupling of EphA/ephrinA signaling and spontaneous activity in neural circuit wiring. J Neurosci 33: 18208-18218.

BENTLEY D, KESHISHIAN H (1982). Pathfinding by peripheral pioneer neurons in grasshoppers. Science 218: 1082-1088.

BLANKENSHIP AG, FELLER MB (2010). Mechanisms underlying spontaneous patterned activity in developing neural circuits. Nat Rev Neurosci 11: 18-29.

BRANDON EP, LIN W, D'AMOUR KA, PIZZO DP DOMINGUEZ B, SUGIURA Y, THODE S, KO C-P, THAL LJ, GAGE FH, LEE K-F (2003). Aberrant patterning of neuromuscular synapses in choline acetyltransferase-deficient mice. J Neurosci 23: 539-549.

CATELA C, SHIN MM, DASEN JS (2015). Assembly and function of spinal circuits for motor control. Ann Rev Cell Dev Biol 31: 669-698.

CHUB, N., O'DONOVAN, MJ (1988). Blockade and recovery of of spontaneous rhythmic activity after application of neurotransmitter antagonists to spinal networks of the chick embryo. J Neurosci 18: 294-306.

DAHM L, LANDMESSER L (1989). The regulation of intramuscular nerve branching during normal development and following activity blockade. Dev Biol130:621-644.

DAHM L, LANDMESSER L (1991). The regulation of synaptogenesis during normal development and following activity blockade. J Neurosci 11: 28-255.

DING R, JANSEN JKS, LAING NG, TONNESEN H (1983). The innervation of skeletal muscles in chickens curarized during early development. JNeurocytol12:887-919.

DOLMETSCH RE, LEWIS RS, GOODNOW CC, HEALY JJ, (1997). Differential activation of transcription factors induced by $\mathrm{Ca}^{2+}$ response amplitude and duration. Nature 386: 855-858.

EBERHARTJ, SWARTZME, KOBLAR SA, PASQUALE EB, KRULLCE (2002). EphA4 constitutes a population-specific cue for motor neurons. Dev Biol 247: 89-101.

EBERHART J, SWARTZ ME, KOBLAR SA, PASQUALE EB, TANAKA H, KRULL CE (2000). Expression of EphA4, ephrin-A2 and ephrin-A5 during axon outgrowth to the hindlimb indicates potential roles in pathfinding. Dev Neurosci 22: 237-250.

GOODMAN CS, BASTIANI MJ, DOE CQ, du LAC S, HELFAND SL, KUWADA JY, THOMAS JB (1984). Cell recognition during neuronal development. Science 225: 1271-1279.

GRILLNER S (1975). Locomotion in vertebrates-central mechanisms and reflex interactions. Physiol Rev 55: 247-304.

HAASE G, DESAUD E, GARCES A, de BOVIS B, BIRLING M, FILLIPI P, SCHMALBRUCH H, ARBER S, de LAPEYRIERE O (2002). GDNF acts through PEA3 to regulate cell body positioning and muscle innervation of specific motor neuron pools. Neuron: 893-905.
HAMBURGER V (1934). The effects of wing bud extirpation on the development of the central nervous system in chick embryos. J Exp Zool 68: 449-494.

HAMBURGER V (1939). The development and innervation of transplanted limb primordia of chick embryos. J Exp Zool 80: 347-389.

HAMBURGER (1975). Cell death in the development of the lateral motor column of the chick embryo. J Comp Neurol 160: 535-546.

HAMBURGER V, BALABANM (1963). Observations and experiments on spontaneous rhythmical behavior in the chick embryo. Dev Biol 7: 533-545.

HAMBURGER V, WENGER E, OPPENHEIM R (1966). Motility in the absence of sensory input. J Exp Zool 162: 133-160.

HANSON MG, LANDMESSER LT (2003). Characterization of the circuits that generate spontaenous episodes of activity in the early mouse spinal cord. $J$ Neurosci 23: $587-600$

HANSON MG, LANDMESSER LT (2004). Normal patterns of spontneous activity are required for correct motor axon guidance and the expression of specific guidance molecules. Neuron 43: 687-701.

HANSON MG, LANDMSSER LT (2006). Increasing the frequency of spontaneous rhythmic activity disrupts pool-specific axon fasciculation and pathfinding of embryonic spinal motoneurons. J Neurosci 26: 12769-12780.

HOLLYDAY M, HAMBURGER V (1976). Reduction of the naturally occurring motor neuron loss by enlargement of the periphery. J Comp Neurol 170: 311-320.

HOLT CE, SCHUMANEM (2013). The central dogma decentralized: new perspectives of RNA function and local translation in neurons. Neuron 80: 648-657.

HORDER TJ, MARTIN K (1978). Morphogenetics as an alternative to chemospecificity in the formation of nerve connections. In: Cell-Cell Recognition, ed ASG Curtis, pp.275-358.

ITOH K, OZAKI M, STEVENS B, FIELDS RD (1997). Activity dependent regulation of $\mathrm{N}$-cadherin in DRG neurons: differential regulation of N-cadherin, NCAM, and L1 by distinct patterns of action potentials. J Neurobio/ 33: 735-748.

KANIA A, JESSELL TM (2003). Topographic motor projections in the limb imposed by LIM homeodomain protein regulation of ephrin-A:EphA interactions. Neuron 38: 581-596.

KANIA A, JOHNSON RL, JESSELL TM (2000). Coordinate roles for LIM homeobox genes in directing dorsoventral trajectory of motor axons in the vertebrate limb. Cell 102: 162-173.

KASTANENKAKV, LANDMESSERLT(2010). In-vivo activation of channelrhodopsin-2 reveals that normal patterns of spontaneous activity are required for motoneuron guidance and maintenance of guidance molecules. J Neurosci 30: 10575-10585.

KASTANENKA KV, LANDMESSER LT (2013). Optogenetic-mediated increases in in-vivo spontaneous activity disrupt pool-specific but not dorso-ventral motoneuron pathfinding. Proc. Natl. Acad. Sci. USA 110: 17528-17533.

KATZ LC, SHATZ CJ (1996). Synaptic activity and the construction of neural circuits. Science 274: 1133-1138.

KEYNES RJ, STIRLING RV, STERN CD, SUMMERBELL D ((1987). The specificity of motor innervation of the chick wing does not depend on the segmental origin of the muscles. Development 99: 565-575.

KRAMER ER, KNOTT L, SU F, DESSAUD E, KRULL CE, HELBACHER F, LEIN R (2006). Cooperation between GDNF/Ret and ephrinA/EphA4 signals for motoraxon pathway selection in the limb. Neuron 50: 35-47.

LANCE-JONES C (1988). The effect of somite manipulation on the development of motoneuron projection patterns in the embryonic chick hind limb. Dev Biol 126: 408-419.

LANCE-JONES C, DIAS M (1991). The influence of presumptive limb connective tissue on motoneuron axon guidance. Dev Biol 143: 93-110.

LANCE-JONESC, LANDMESSERL(1981a). Pathway selection by chick motoneurons during normal development. Proc $R$ Soc Lond B 214: 1-18.

LANCE-JONES C, LANDMESSER L (1981b). Pathway selection by embryonic chick motoneurons in an experimentally altered environment. Proc $R$ Soc Lond B 214: 19-52.

LANDMESSER L (1978). The development of motor projection patterns in the chick hind limb. J Physiol Lond 284: 391-414.

LANDMESSER L, DAHM L, TANG J, RUTISHAUSER U (1990). Polysialic acid as a regulator of intramuscular nerve branching during embryonic development. Neuron 4: 655-667. 
LANDMESSER L, MORRIS DG (1975). The development of functional innervation in the hindlimb of the chick embryo. J Physiol Lond 249: 301-327.

LANDMESSER LT, O'DONOVAN MJ (1984a). Activation patterns of embryonic chick hindlimb muscles recorded in-ovo and in an isolated spinal cord preparation. $J$ Physiol Lond 347: 189-204.

LANDMESSER LT, O'DONOVAN MJ (1981b). The activation patterns of embryonic motoneurons projecting to inappropriate muscles. J Physiol Lond 347: 205-224.

LAW C, SCHAAN-PROFES M, LEVESQUE M, KALTSCHMIDT JA, VERHAGE M, KANIAA (2016). Normal molecular specification and neurodegenerative diseaselike death of spinal neurons lacking SNARE-asociated synaptic protein Munc18-1. J Neurosci 36: 561-576.

LURIA V, KRAWCHUK D, JESSELL TM, LAUFER E, KANIA A (2008). Specification of motor axon trajectory by ephrin-EphB signalling: symmetrical control of axon pathfinding in the developing limb. Neuron: 60: 1039-1053.

MILNER LD, LANDMESSER LT (1999). Cholinergic and GABAergic inputs drive patterned spontaneous activity before target contact. J Neurosci 19: 3007-3022.

MING GL, HENLEY J, TESSIER-LAVIGNE M, SONG HJ, POO M-M (2001). Electrical activity modulates growth cone guidance by diffusible factors. Neuron 4: 441-452

MOMOSE-SATOY, NAKAMORIT, SATOK(2012a). Spontaneous depolarization wave in the mouse embryo: origin and large-scale propagation over the CNS identified with voltage-sensitive dye imaging. Eur J Neurosci 35: 1230-1241.

MOMOSE-SATO Y, NAKAMORI T, SATO K. (2012b). Parmacological mechanisms underlying switching from large scale depolarization wave to segregated activity in the mouse central nervous system. Eur J Neurosci 35: 1242-1252.

MOODYWJ, BOSMAMM (2004). Ion channel development, spontaneous activity, and activity dependent development in nerve and muscle. Physiol Rev 85: 883-941.

NISHIMARU H, IZUKA M, OZAKI S, KUDO N (1996). Spontaneous motoneuronal activity mediated by glycine and GABA in the spinal cord of rat fetuses in vitro. J Physiol Lond 497: 131-143.

O'DONNELL M, CHANCE RK, BASHAW GJ (2009). Axon growth and guidance: receptor regulation and signal transduction. Annu Rev Neurosci 32: 383-412.

O'DONOVAN MJ, CHUB N, WENNER P (1998). Mechanisms of spontaneous activity in developing spinal networks. J Neurobiol 37: 131-145.

OPPENHEIM RW (1991). Cell death during the development of the nervous system. Ann Rev Neurosci 14: 453-501.

PATEL TD, KRAMER I, KUCERA J, NIEDERKOFLER V, JESSELL TM, ARBER S, SNIDER WD (2003). Peripheral NT3 signaling is required for ETS protein expression and central patterning of proprioceptive sensory afferents. Neuron 403-416.

PHELAN, KA, HOLLYDAY M (1990). Axon guidance in muscleless chick wings: the role of muscle cells in motoneuronal pathway selection and muscle nerve formation. J Neurosci 10: 2699-2716.

PHELAN, KA, HOLLYDAY M (1991). Embryonic development and survival of brachial motoneurons projecting to muscleless chick wings. J Comp Neuro/311:313-320.
PITTMANN R, OPPENHEIM RW (1978). Neuromuscular blockade increases motoneuron survival during normal cell death in the chick embryo. Nature 271:364-366.

POLIAK S, MORALES D, CROTEAU LP, KRAWCHUK D, PALMESIO E, MORTON S, CLOUTIER JF, CHARRON F, DALVA MB, ACKERMAN SL, KAO TJ, KANIA $A$ (2015). Synergistic integration of netrin and ephrin axon guidance signals by spinal motor neurons. eLife DOI: 10.7554/eLife 10841.001

PROVINE RR, SHARMA SC, SANDEL TT, HAMBURGER V (1970). Observations and experiments on spontaneous rhythmical behavior in the chick embryo. Proc Nat Acad Sci USA 65: 508-515

RAMON y CAJAL (1911). Histologie du systeme nerveux de l'homme et de vertebres, vol 1, Madrid: Instituto Ramon y Cajal.

ROMANES GJ (1964). The motor pools of the spinal cord. In Progress in Brain Research. (Ed. JC Eccles and JP Shade). Organization of the Spinal Cord, Vol 11. New York: Elsevier. pp 93-119.

RUTISHAUSER U, LANDMESSER L (1996). Polysialic acid in the vertebrate nervous system: a promotor of plasticity in cell-cell interactions. Trends Neurosci 19:422-427.

STIRLING RV, SUMMERBELL D (1981). The innervation of dorsoventrally reversed chick wings. Evidence that motor axons do not actively seek out their appropriate targets. J Embryol Exp Morph 61: 233-247.

TABAK J, RINZEL J, O'DONOVAN MJ (2001). The role of activity dependent network depression in the expression and self-regulation of spontaneous activity in the developing spinal cord. J Neurosci 15: 8966-8978.

TANG J, LANDMESSER L (1993). Reduction in intramuscular nerve branching and synaptogenesis is correlated with decreased motoneuron survival. $J$ Neurosci 13: 3095-3103.

TANG J, LANDMESSER L, RUTISHAUSER U (1992). Polysialic acid influences specific pathfinding by avian motoneurons. Neuron 8: 1031-1044.

TRIPODI M, ARBER S (2012). regulation of motor circuit assembly by spatial and temporal mechanisms. Curr Opin Neurobiol 22: 615-623.

TRIPODI M, STEPIEN AE, ARBER S (2011). Motor antagonism exposed by spatia segregation and timing of neurogenesis. Nature 479: 61-66.

TSUCHIDA T, ENSINI M, MORTON SB, BALDASARRE M, EDLUND T, JESSELL TM, PFAFF SM (1994). Topographic organization of embryonic motor neurons defined by expression of LIM homeobox genes. Cell 79: 957-970.

TESSIER-LAVIGNE M, GOODMAN CS (1996). The molecular biology of axon guidance. Science 274: 1123-1132.

WATT SD, GU X, SMITH RD, SPITZER NC (2000). Specific frequencies of spontaneous $\mathrm{Ca} 2+$ transients upregulate GAD 67 transcipts in spinal neurons. Mol Cell Neurosci. 16: 376-387.

WEISS P (1937). Further experimental investigations on the phenomenon of homologous response in transplanted amphibian limbs. II. Nerve regeneration and the innervation of transplanted limbs. J Comp Neurol 66: 481-535. 


\section{Further Related Reading, published previously in the Int. J. Dev. Biol.}

CXCL14 expression during chick embryonic development

Christopher T. Gordon, Christine Wade, Inigo Brinas and Peter G. Farlie

Int. J. Dev. Biol. (2011) 55: 335-340

https://doi.org/10.1387/ijdb.103258cg

Molecular cloning of chicken Cecr2 and its expression during chicken embryo development Jingchen Chen, Gabriela Morosan-Puopolo, Fangping Dai, Jianlin Wang and Beate Brand-Saberi

Int. J. Dev. Biol. (2010) 54: 925-929

https://doi.org/10.1387/ijdb.092933jc

Oligodendrocyte development in the embryonic brain: the contribution of the plp lineage

Barbara Le Bras, Elli Chatzopoulou, Katharina Heydon, Salvador Martínez, Katzuhiko Ikenaka, Laetitia Prestoz, Nathalie Spassky, Bernard

Zalc and Jean-Léon Thomas

Int. J. Dev. Biol. (2005) 49: 209-220

http://www.intjdevbiol.com/web/paper/041963bl

Notch activity is required to maintain floorplate identity and to control neurogenesis in the chick hindbrain and spinal cord Isabelle le Roux, Julian Lewis and David Ish-Horowicz

Int. J. Dev. Biol. (2003) 47: 263-272

http://www.intjdevbiol.com/web/paper/12755331

Patterning of the vertebrate ventral spinal cord

Alisa Poh, Asanka Karunaratne, Gabriel Kolle, Ning Huang, Emma Smith, Joanna Starkey, Daying Wen, Ian Wilson, Toshiya Yamada and Murray Hargrave

Int. J. Dev. Biol. (2002) 46: 597-608

http://www.intjdevbiol.com/web/paper/12141448

Early neurogenesis in Amniote vertebrates

N M Le Douarin

Int. J. Dev. Biol. (2001) 45: 373-378

http://www.intjdevbiol.com/web/paper/11291868

Coexpression of HNF-3 beta and IsI-1/2 and mixed distribution of ventral cell types in the early neural tube

A Ruiz i Altaba

Int. J. Dev. Biol. (1996) 40: 1081-108

http://www.intjdevbiol.com/web/paper/9032013

5 yr ISI Impact Factor $(2016)=2.421 \mathrm{w}$
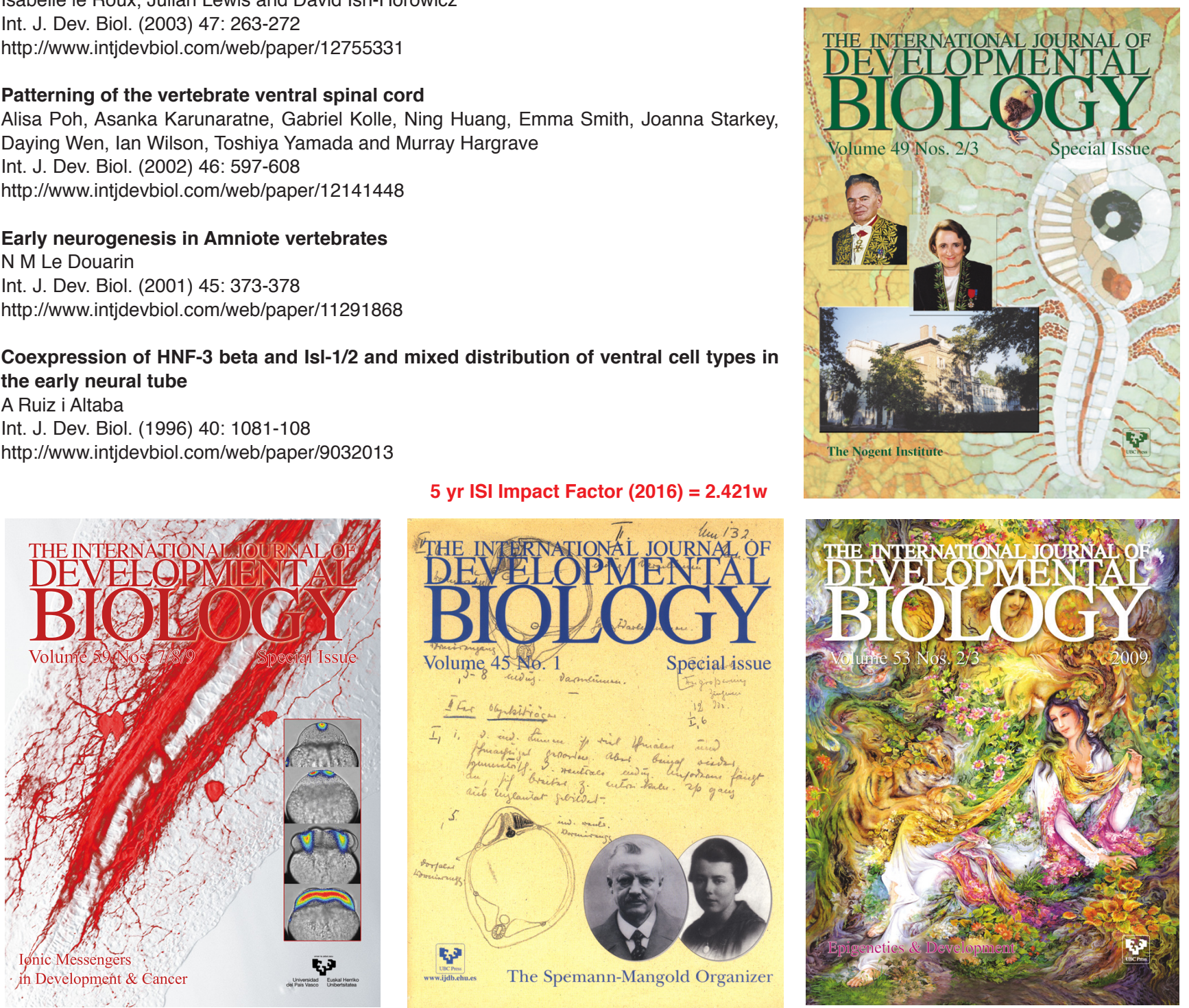